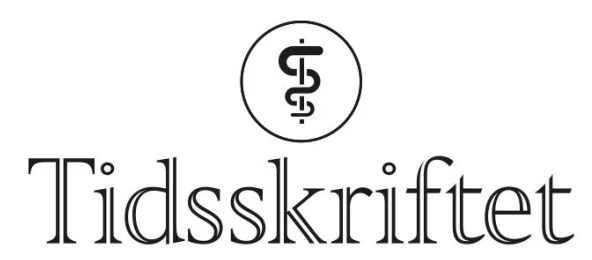

DEN NORSKE LEGEFORENING

\title{
Pasient med alvorlig covid-19 behandlet med rekonvalesensplasma
}

KORT KASUISTIKK

\section{MICHAEL HAHN}

michael.hahn@helse-fonna.no

Klinikk for akuttmedisin

Haugesund sjukehus

Michael Hahn er spesialist $i$ anestesiologi og overlege.

Forfatteren har fylt ut ICMJE-skjemaet og oppgir ingen interessekonflikter.

\section{MARIA ELENA HUANCA CONDORI}

Klinikk for akuttmedisin

Haugesund sjukehus

Maria Elena Huanca Condori er spesialist i anestesiologi med videreutdanning i intensivmedisin (SSAI Diploma) og seksjonsoverlege.

Forfatteren har fylt ut ICMJE-skjemaet og oppgir ingen interessekonflikter.

\section{ATLE TOTLAND}

Hjerte- og lungeavdelingen

Haugesund sjukehus

Atle Totland er overlege.

Forfatteren har fylt ut ICMJE-skjemaet og oppgir ingen interessekonflikter.

\section{EINAR K. KRISTOFFERSEN}

Avdeling for immunologi og transfusjonsmedisin

Haukeland universitetssjukehus

og

Klinisk institutt 2

Universitetet i Bergen

Einar K. Kristoffersen er avdelingssjef og professor II.

Forfatteren har fylt ut ICMJE-skjemaet og oppgir ingen interessekonflikter.

\section{TOR AUDUN HERVIG}

Eining for immunologi og transfusjonsmedisin Haugesund sjukehus

og

Klinisk Institutt 2

Universitetet i Bergen

Tor Audun Hervig er overlege og professor.

Forfatteren har fylt ut ICMJE-skjemaet og oppgir ingen interessekonflikter. 


\section{Covid-19 kan føre til livstruende sykdom. I påvente av vaksinasjon og dokumentert effektiv behandling utprøves flere alternative behandlinger. Dette er den første publiserte beskrivelsen av en pasient som fikk behandling med rekonvalesensplasma i Norge.}

En mann i 7o-årene ble innlagt etter åtte dagers sykehistorie med febrilia. Siste døgnet før innleggelse tilkom akutt forverring med tungpustethet og forvirringstilstand. Pasienten var fra tidligere frisk og brukte kun protonpumpehemmer som fast medikasjon. Da han ankom sykehuset, var han våken, men ikke orientert for tid eller sted. Han hadde $\mathrm{SpO}_{2}$ på 88 \% med $15 \mathrm{l} / \mathrm{min}$ oksygen på reservoarmaske, respirasjonsfrekvens 42 per minutt, temperatur $40,7{ }^{\circ} \mathrm{C}$, hjertefrekvens på $114 \mathrm{slag} / \mathrm{min}$ og blodtrykk 134/64 mm Hg. Første blodgass med oksygen $15 \mathrm{l} / \mathrm{min}$ viste $\mathrm{pH}$ 7,56 (7,35-7,45), $\mathrm{PaO}_{2}$ 6,2 kPa (9,6-12,4), pCO $3,4 \mathrm{kPa}$ (4,7-5,9), bikarbonat $22 \mathrm{mmol} / \mathrm{l}(22-26)$ og laktat 2,9 mmol/l (o,4-1,8). Røntgen thorax viste diffust utbredte fortetninger bilateralt. På sterk mistanke om covid-19 ble pasienten flyttet til isolat på intensivavdelingen. Grunnet alvorlig respirasjonssvikt ble han raskt intubert og tilkoblet respirator.

Respiratorbehandlingen forløp relativt ukomplisert første uken, og han ble ekstubert dag 7 etter innleggelse. Neste dag ble han igjen intubert grunnet respirasjonssvikt. Den respiratoriske situasjonen forverret seg, og både oksygeneringen og ventilasjonen ble dårligere (figur 1a-b). Kliniske funn var nå forenlig med klassisk akutt lungesviktsyndrom (ARDS) med stive lunger, og CT thorax dag 15 viste betydelige lungeforandringer og perifere lungeemboluser (figur 2). 
$\mathrm{O}_{2}-\mathrm{ratio}\left(\mathrm{PaO}_{2} / \mathrm{FiO}_{2}\right)$

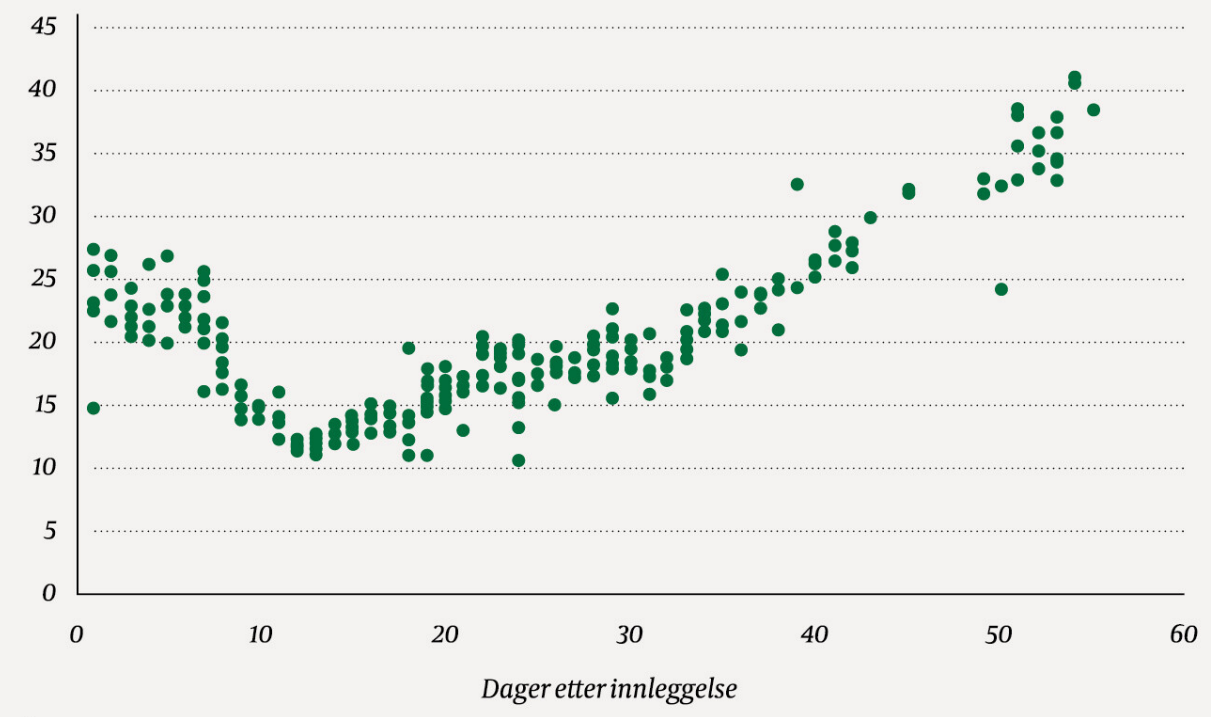

a.

Arteriell $\mathrm{CO}_{2}$-verdi $\left(\mathrm{pCO}_{2}\right)$

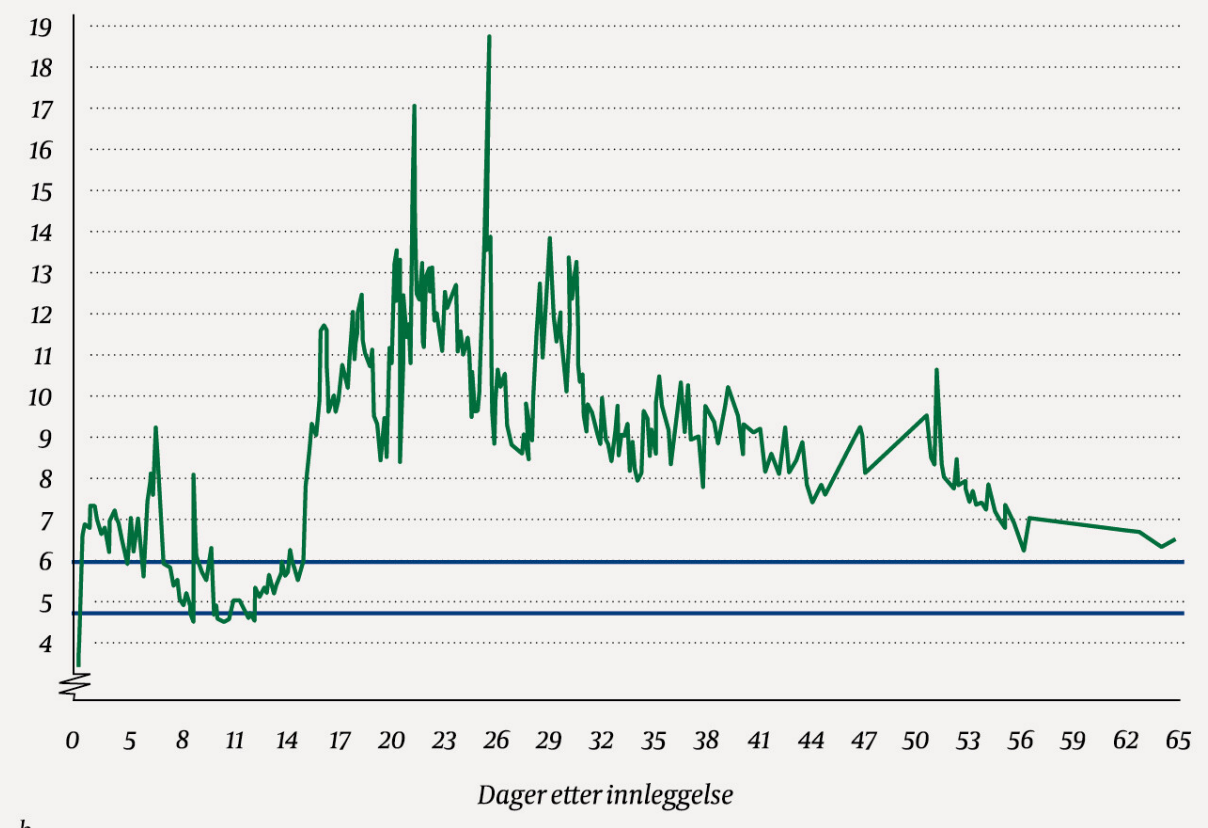

b.

Figur 1 Pasientens forløp av a) O2-ratio $\left(\mathrm{PaO}_{2} / \mathrm{FiO}_{2}\right)$ og b) arteriell $\mathrm{CO}_{2}$-verdi $\left(p \mathrm{CO}_{2}\right)$. 


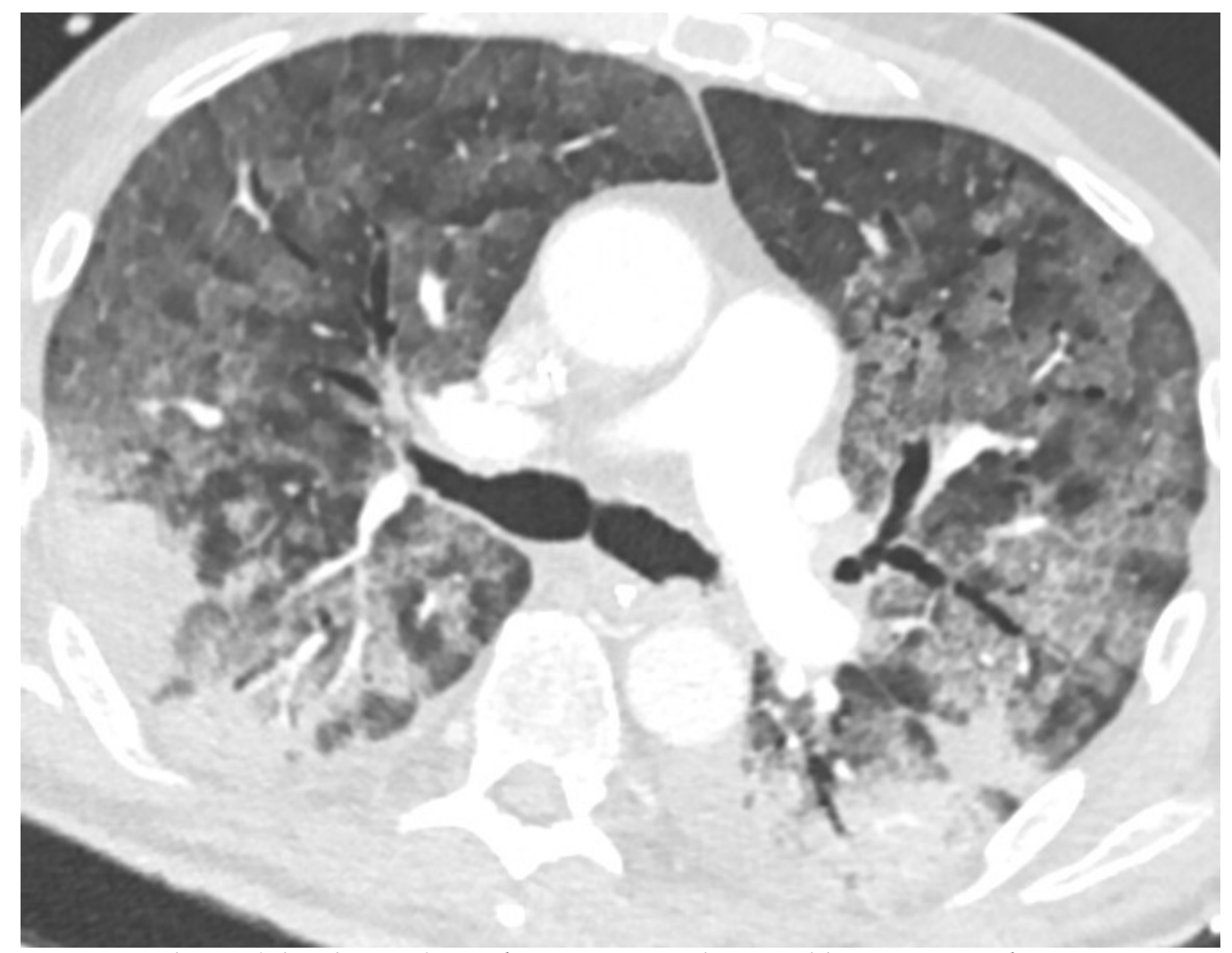

Figur 2 CT thorax (aksiale snitt) tatt dag 15 viser uttalt mosaikkmønster med matglassforandringer i begge lunger.

For å klare å ventilere pasienten tilstrekkelig, ble han i en lengre periode dypt sedert og muskelrelaksert, med både boluser og kontinuerlig infusjon med muskelrelakserende midler over flere dager. Det ble fors $ø$ kt mageleie i flere omganger, uten bedring, og pasienten måtte snus tilbake i ryggleie grunnet vanskelig ventilering med betydelig $\emptyset$ kning av $p \mathrm{CO}_{2}$ (figur 1 ).

Sars-CoV-2 ble påvist da han ankom sykehuset, men ellers var det ingen vekst i blodkulturer, urin eller bronkial skylleprøve. Antibiotikabehandling var langvarig, initialt i forløpet empirisk og kontinuert grunnet feber og høy CRP, selv om det ikke ble påvist agens. Sirkulatorisk var pasienten stabil og stort sett uten behov for vasopressor. Han hadde flere episoder med atrieflimmer, som ble behandlet både medikamentelt og med elektrokonvertering. Kreatininverdien steg opptil $150 \mu \mathrm{mol} / \mathrm{l}$ (60-105), men pasienten utviklet ikke behandlingskrevende nyresvikt.

Nasofarynksprøve for sars-CoV-2 var fortsatt positiv dag 23. Pasienten var etter lang tids intensivbehandling svært preget, med betydelig muskelsvinn og vedvarende respirasjonssvikt. Om pasienten ville overleve den aktuelle sykdommen, var usikkert. Behandling med rekonvalesensplasma ble derfor diskutert med blodbanken. Det var på dette tidspunktet kommet oppfordring fra helsemyndighetene i EU om å bruke rekonvalesensplasma. Det ble fremskaffet plasma fra to blodgivere, og pasienten fikk transfusjon med rekonvalesensplasma dag 31. Begge blodgiverne hadde gjennomgått verifisert covid-19-infeksjon, og den ene hadde i tillegg fått påvist IgG-antistoff mot sarsCoV-2 i høyt nivå. Til sammen $900 \mathrm{ml}$ rekonvalesensplasma ble derfor transfundert, med langsom infusjonshastighet.

I løpet av det neste døgnet ble pasienten afebril, og sars-CoV-2-test fra nasofarynks tatt dag 32 var negativ. To påfølgende prøver fra lunge var også negative. Pasienten ble flyttet ut av isolasjon dag 36 og fra intensivavdelingen dag 63. Han var da uten respirasjonsstøtte.

\section{Diskusjon}


Denne kasuistikken er en kort oppsummering av et langvarig og komplisert intensivforløp hos en pasient med covid-19. Pasienten var en tidligere frisk mann med CFS-skår (clinical frailty scale) på 1 (veldig sprek) (1).

Covid-19 er en ny sykdom, og hos denne pasienten ble alternative medikamenter og behandlingsalternativer fortløpende diskutert. Dag 31 var pasienten kritisk dårlig, og ytterligere terapeutiske tiltak var nødvendig. Ut ifra tilgjengelig litteratur ble passiv immunisering ved hjelp av rekonvalesensplasma vurdert som beste alternativ. Passiv immunisering brukes i behandling av flere infeksjonssykdommer (2,, 3$)$, inkludert sars (4). Behandling med rekonvalesensplasma ved covid-19 var allerede forsøkt i flere land (5, 6 ), og vi fant det derfor etisk rett å gjennomføre behandlingen i samråd med pasientens familie. På dette tidspunktet var ikke validerte analyser for nøytraliserende antistoff mot sars-CoV-2 tilgjengelig i Norge. I litteraturen og i nylig iverksatte protokoller var ingen veldefinert plasmadose angitt. På bakgrunn av pasientens alvorlige tilstand og usikkerhet knyttet til forekomst av nøytraliserende antistoff i donorplasma, ble det bestemt å bruke to blodgivere.

Siden pasienten hadde fått intensivbehandling både i forkant av og parallelt med plasmatransfusjonen, kan man ikke med sikkerhet si hvor stor betydning infusjon med rekonvalesensplasma hadde. Men kvelden for plasmatransfusjonen sammenfaller med et vendepunkt i sykehistorien. Ut fra både kliniske og laboratoriemessige parametre går pasienten fra en utvikling med langsom forverring til gradvis bedring (figur 1). Dessverre ble det ikke testet for sars-CoV-2 rett før transfusjonen.

Etter at transfusjonen ble gjennomført, har det kommet en artikkel som tyder på at rekonvalesensplasma kan bedre overlevelsen hos ikke-intuberte pasienter (7.). Hos intuberte pasienter er kunnskapsgrunnlaget ennå for lite. I tillegg er det godt dokumentert at transfusjon av rekonvalesensplasma er trygt (ㅇ). Dette er oppmuntrende når man nå planlegger å tilby pasienter rekonvalesensplasma i en nasjonal monitoreringsstudie og i en randomisert klinisk studie på enkelte sykehjem.

Pasienten har gitt samtykke til at artikkelen blir publisert.

Artikkelen er fagfellevurdert.

\section{LITTERATUR}

1. Rockwood K, Song X, MacKnight C et al. A global clinical measure of fitness and frailty in elderly people. CMAJ 2005; 173:489-95. [PubMed][CrossRef]

2. Johansen JS, Westergren T, Lingaas E. Profylaktisk behandling etter varicellaeksponering. Tidsskr Nor Legeforen 2011; 131:1645-8. [PubMed][CrossRef]

3. Rothstein SS, Goldman HS, Arcomano A. Passive immunization for hepatitis B. J Oral Maxillofac Surg 1982; 40:34-7. [PubMed][CrossRef]

4. Cheng Y, Wong R, Soo YO et al. Use of convalescent plasma therapy in SARS patients in Hong Kong. Eur J Clin Microbiol Infect Dis 2005; 24: 44-6. [PubMed][CrossRef]

5. Ahn JY, Sohn Y, Lee SH et al. Use of convalescent plasma therapy in two COVID-19 patients with acute respiratory distress syndrome in Korea. J Korean Med Sci 2020; 35: e149. [PubMed][CrossRef]

6. Tanne JH. Covid-19: FDA approves use of convalescent plasma to treat critically ill patients. BMJ 2020; 368: m1256. [PubMed][CrossRef]

7. http://dx.doi.org/10.1101\%2F2020.05.20.20102236 doi:10.1101/2020.05.20.20102236. Liu STH, Lin HM, Baine I et al. Convalescent plasma treatment of severe COVID-19: A matched control study. MedRxiv 2020.[CrossRef]

8. http://dx.doi.org/10.1101\%2F2020.05.12.20099879 doi: 10.1101/2020.05.12.20099879. Joyner MJ, Wright RS, Fairweather D et al. Early safety indicators of COVID-19 convalescent plasma in 5,0oo patients 2020. MedRxiv 2020.[CrossRef] 
Publisert: 26. juni 2020. Tidsskr Nor Legeforen. DOI: 10.4045/tidsskr.20.0501

Mottatt 4.6.2020, første revisjon innsendt 15.6.2020, godkjent 24.6.2020.

Publisert under åpen tilgang CC BY-ND. Lastet ned fra tidsskriftet.no 26. april 2023. 